\title{
The moderating role of self-regulated learning in job characteristics and attitudes towards web-based continuing learning in the airlines workplace
}

\author{
Xiao-fan Lin \\ School of Education Information Technology, South China Normal University \\ Jyh-Chong Liang, Chin-Chung Tsai \\ Program of Learning Sciences, National Taiwan Normal University \\ Qintai Hu \\ School of Education Information Technology, South China Normal University
}

\begin{abstract}
With the increasing importance of adult and continuing education, the present study aimed to examine the factors that influence continuing web-based learning at work. Three questionnaires were utilised to investigate the association of the job characteristics from Karasek et al.'s (1998) job demand-control-support model and the self-regulated learning with web-based continuing learning; exploratory factor analyses indicate their adequate reliability and validity. A sample of 203 employees of an airline company completed three questionnaires. The path analysis reveals that job demands did not have any significant correlation with any other variables. However, job control, social support and self-regulated learning constituted significant predictors of attitudes towards web-based continuing learning. Furthermore, self-regulated learning mediated job characteristics and attitudes. In conclusion, this is one of the few studies to consider perceptions of both personal online learning (i.e., self-regulated learning and attitudes towards web-based continuing learning) and work-related variables (i.e., job characteristics). The study advances interdisciplinary perspectives on education, information and communications technology and psychology, which has implications for continuing adult education and successful implementation of online workplace learning.
\end{abstract}

\section{Introduction}

At a time of rapid social change and fierce business competition, the majority of employees confront long working hours, high pressure and intense customer-related demands. Studies have suggested that web-based continuing learning could offer the flexibility of learning and could enrich learning resources to improve employees' knowledge, skills and attitudes (e.g., Za, Spagnoletti, \& North-Samardzic, 2014). Web-based continuing learning has become more popular in the workplace as a cost-effective form of continuing education for increasing training efficiency (Lin, 2011). Positive job characteristics and professional development may be facilitated when employees are involved in a motivated work environment and continuing learning (Thorpe \& Gordon, 2012). As the airline business is becoming extremely competitive, it is critical for airline corporations to improve employees' knowledge, skills and attitudes via the advantages of web-based continuing learning (de Brito Neto, Smith, \& Pedersen, 2014).

Studies have indicated that work-related variables (i.e., work conditions, social support and social environment) may support employees' e-learning in the workplace. For instance, employees' motivation towards e-learning may depend on the perceived usefulness of the work conditions (B. Cheng, Wang, Moormann, Olaniran, \& Chen, 2012). Joo, Lim, and Park (2011) verified that social support and learning flow could positively affect employees' e-training satisfaction in the workplace. Meanwhile, some researchers have argued that individual factors such as personal initiative should be taken into account (e.g., McLoughlin \& Lee, 2010; Wong \& Abu Bakar, 2009). As exemplified in Taris and Kompier's (2004) study, employees with a higher degree of personal initiative demonstrated more working strategies and effort expenditure in workplace learning activities than those with low initiative. However, there are still limitations worth addressing. Numerous research studies have delved into either online personal characteristics (e.g., initiative, 
self-regulation) or workplace-related variables (e.g., job demands, work conditions) to facilitate better workplace learning, while few have considered both these variables simultaneously.

\section{Literature review}

\section{Job characteristics and web-based learning}

To understand psychological job characteristics, job content characteristics questionnaires have been developed in line with the demand-control-support model (Karasek et al., 1998). This model is mainly used to analyse existing job characteristics in an organisation and consists of three scales: job demands, job control and social support. First, job demands refers to the work burden that an individual carries. Second, job control refers to what an individual can control while working, including decisions related to work, as well as some needed professional work skills (Willemse, de Jonge, Smit, Depla, \& Pot, 2012). Social support (i.e., workrelated support from supervisors and colleagues) might not only be a source of pressure, but could also have a regulating effect on individuals’ psychological job stressors (Y. Cheng, Chen, Burr, Chen, \& Chiang, 2014).

In the last decade, several studies have been carried out to validate whether these questionnaires on job characteristics may be administered to assess the predictors for explaining work-related learning. For instance, Chiu and Tsai (2014) found that job control is positively associated with their attitudes towards web-based continuing learning when nurses are given more opportunities for self-determination at work. Under this condition, the nurses were positive and motivated to learn skills online, and their perception of control and, consequently, their attitudes towards web-based continuing learning improved. Chen (2010) found that social support responses to employees' needs have positive effects on satisfaction with and involvement in elearning environments. However, the relationship between job characteristics and web-based continuing learning remains unclear. Some studies have suggested that positive job characteristics could improve employees' perceived usefulness of web-based continuing learning (e.g., Chiu, Tsai, \& Fan Chiang, 2013). Nevertheless, some have argued that the role of job characteristics is vague, and others have found that job characteristics do not contribute effectively to workplace learning (e.g., Gijbels, Raemdonck, \& Vervecken, 2010). Hence, job characteristics might not directly affect the effect of web-based continuing learning. Their role as possible influential factors for web-based continuing learning still needs to be examined.

\section{Self-regulated learning and web-based learning}

Self-regulated learning is regarded as a metacognitive process in which learners are actively involved in their own learning, with goal setting, cognition, motivation, behaviour and context (Zimmerman, 2002). Selfregulated strategies are beneficial in web-based learning (e.g., McLoughlin \& Lee, 2010; Tseng, Liang, \& Tsai, 2014). Learners who are more adapted to self-regulation develop better learning strategies and achieve better academic performances than those who lack self-regulation (Zimmerman \& Kitsantas, 2014). Moreover, Chen and Kao (2012) succeeded in promoting employees' learning motivation to support selfregulated learning strategies (i.e., self-reflection and sharing experience) on workplace experiences. Additionally, Chai, Wong, and King (2016) showed that appropriate self-regulatory activities and strategies with mobile devices are vital for achieving one's learning goals and tasks in twenty-first-century learning practices. According to a review of research trends regarding self-regulated learning, it is essential for researchers to examine learners’' online self-regulation (McLoughlin \& Lee, 2010).

\section{Attitudes towards web-based continuing learning}

Attitudes towards web-based continuing learning (AWCL) are regarded as an important predictor of learners' willingness to learn and their interest in learning through web-based learning environments (Peng, Tsai, \& $\mathrm{Wu}, 2006)$. Studies have suggested that web-based continuing learning is beneficial for employees in gaining new skills and information (Liang, Wu, \& Tsai, 2011). The professional advancement strategy conducted by numerous airlines through e-learning reflects the worldwide upward trend in the adoption of web-based 
continuing learning (de Brito Neto et al., 2014). Therefore, exploring employees' attitudes toward AWCL is an important research issue.

\section{The relationship between job characteristics, self-regulated learning and web-based continuing learning}

For the past several decades, the importance of self-regulation has been emphasised for success in online continuing learning (e.g., Delen, Liew, \& Willson, 2014; Lehmann, Hähnlein, \& Ifenthaler, 2014) as this selfdirective process transforms learners' mental abilities into academic skills: self-awareness, self-motivation and behavioural skill (Zimmerman, 2002, pp. 64-66). In earlier hypotheses, job characteristics were deemed to be related to employees' web-based continuing learning, but may not directly impact it. Furthermore, several studies have suggested that self-regulated learning may be a mediator in the relationship between personal characteristics and online learning performance (e.g., Lin, 2011; Tseng et al., 2014). Hence, further research is needed to advance our understanding of how employees' job characteristics (i.e., work-related variables) and self-regulation (i.e., personal variables) affect their web-based continuing learning. The current study is one of the few to consider the role of personal and workplace-related variables in facilitating webbased continuing learning. It attempts to verify the extent to which self-regulated learning mediates the relationship between employees’ job characteristics and web-based continuing learning.

\section{Research questions}

The participants in this study were from a well-known international airline corporation in the China region. The airline focused on blended job training for employees, which relied on the Airlines e-Academy constructed in 2009. SumTotal learning management system is at the core of the Airlines e-Academy, which includes the examination system and e-training system. The objectives of the e-training are the orderly control of the job training implementation development, the integration of e-training resources and the management of participants' learning records. The trainees were employees of the airline, especially new employees. The anticipated outcomes of the blended job training are that the trainees achieve the training objectives related to occupational abilities and that they are able to meet specific job requirements.

This study aimed to explore the relationships between the airline employees' perceptions of job characteristics, self-regulated learning and their AWCL. Consequently, the research questions of this study were as follows:

- $\quad$ Are the instruments used in this study reliable for measuring airline employees' job characteristics, self-regulated learning and AWCL?

- What are the relationships between airline employees' job characteristics, self-regulated learning and AWCL?

- What roles do the airline employees' self-regulated learning and job characteristics play in their AWCL?

\section{Method}

\section{Participants}

The participants in this study were 203 employees (52 females, 151 males) from the airline. The population was determined by the maximum number of employees allowed to participate by the airline corporations (i.e., 203). This study shares a similarity in the relative small number of respondents with de Brito Neto et al.'s (2014) study (148 attendants) and Weigl, Müller, Hornung, Leidenberger, and Heiden's (2014) study (118 attendants), which employed a sample group of participants from airlines. The sample was stratified into two demographic genders (males and females); for each gender three main departments were chosen from the head office. These three departments deal with attendants, safety and operations. The participants' gender ratio selected roughly corresponds to the actual population gender ratio. The mean age of the employees who 
participated in the study was approximately 25 years $(S D=4.41)$, while the length of work experience ranged from 0.5 to 6 years, with an average of 2.1 years $(S D=2.1)$. The majority of the participants were new employees, as they are required to take part in web-based continuing learning to be qualified for their positions. In addition, when responding to the questionnaires, almost all of the employees reported that they had experience in web-based continuing learning.

\section{Data collection and ethical considerations}

To validate the questionnaires, the participants were required to have experience in professional development based on web-based learning. Data collection took place at the end of their courses in a blended learning environment. All participants had at least 5 months' experience in accomplishing the course tasks related to occupational abilities in a web-based learning environment. Prior to answering the questionnaires, the employees recruited for this study were informed that their participation was voluntary and anonymous. They were assured that their responses would be treated confidentially, with the right to withdraw from the survey at any time. Furthermore, their permission signatures in the finished questionnaires were regarded as consent to participate. This way of handling ethical considerations is similar to other questionnaire survey studies (e.g., Liang et al., 2011).

\section{Job content characteristics questionnaire}

To investigate the employees' perceptions of job characteristics, self-regulated learning and AWCL, three instruments, all using a 5-point Likert scale (from 1 strongly disagree to 5 strongly agree), were used in this study. The job content characteristics questionnaire was developed by Chiu et al. (2013) based on the job strain model (Karasek et al., 1998). The 20-item questionnaire was grouped into three scales: job demands, job control and social support. The $\alpha$ coefficients for these three dimensions generated by Chiu et al. (2013) were $0.79,0.78$ and 0.90 , respectively, whereas the $\alpha$ coefficients in this study were $0.74,0.70$ and 0.83 , respectively, which indicates appropriate reliability. The job demand scale investigated the employees' perceptions of the psychological job demands (e.g., work fast, excessive work and concentrate on the job for a long time). The job control scale consisted of two components with regard to decision authority (e.g., influential opinion, freedom to make decisions and being allowed to make one's own decisions) and skill discretion (e.g., creative work, learning new things and high level of skills). The social support scale examined employees' perceptions of work-related support from their co-workers (e.g., friendly, perform their duties well and provide help when needed).

\section{Self-regulated learning questionnaires}

To explore the employees' perceptions of self-regulated learning, this study developed a questionnaire modified from K.-H. Cheng, Liang, and Tsai (2013). The original questionnaire included four phases of selfregulated learning (i.e., planning, controlling, monitoring and reflecting). As many empirical studies have revealed that self-regulated learning might consist of two levels (Pintrich, 2000), K.-H. Cheng et al. (2013) proposed a two-phase model for self-regulated learning (i.e., basic and advanced levels). Moreover, the reliability coefficients (Cronbach's alpha value) validated by K.-H. Cheng et al. (2013) were basic selfregulated learning (0.78) and advanced self-regulated learning (0.87). The $\alpha$ coefficients in this study were basic self-regulated learning (0.77) and advanced self-regulated learning (0.81), demonstrating appropriate internal consistency. Thus, the self-regulated learning questionnaire developed in this study consisted of two scales with 10 items, namely basic self-regulated learning (i.e., task definition, planning and goal setting) and advanced self-regulated learning (i.e., controlling, monitoring and reflecting). The following describes the two scales of the self-regulated learning questionnaire. The basic self-regulated learning scale assessed the extent to which employees prefer to plan or set goals for relevant learning tasks in web-based continuing learning. The advanced self-regulated learning scale measured the extent to which employees attach importance to monitoring their learning processes, engaging in critical self-reflective thinking, and evaluating their learning outcomes in the web-based continuing learning environments. 


\section{AWCL questionnaires}

The AWCL survey was developed by Liang et al. (2011) and consisted of four scales with 27 items: usefulness $(\alpha=0.96)$, ease of use ( $\alpha=0.95)$, behaviour $(\alpha=0.85)$, and affection $(\alpha=0.95)$, which showed high reliability. Compared with the $\alpha$ coefficients generated from Liang et al.'s (2011) study, the $\alpha$ coefficients in this study were $0.89,0.82,0.85$ and 0.87 , respectively, indicating that AWCL is a reliable questionnaire for assessing airlines employees' attitudes towards web-based continuing learning. The perceived usefulness scale assessed the extent to which employees perceived the helpful and useful influence of web-based continuing learning (e.g., "Web-based continuing learning helps me attain better learning outcomes"). The perceived ease of use scale attempted to measure the employees' perceptions of whether it is easy to use web-based continuing learning (e.g., "It is convenient to receive training on the job using web-based continuing learning”). The behaviour scale assessed the employees' willingness to use web-based continuing learning (e.g., "I hope to use web-based continuing learning more often"). In addition, the affection scale aimed at evaluating the extent to which the employees' feelings regarding web-based continuing learning were positive or negative (e.g., "Participating in web-based continuing learning makes me feel anxious"). Some items of the affection scale were stated in reverse (e.g., "Participating in web-based continuing learning makes me feel awkward or uncomfortable'), and participants' responses were thus scored accordingly. The participants with higher average scores on the affection scale felt less anxiety regarding web-based continuing learning.

\section{Data analysis}

First, exploratory factor analysis was employed to validate the three surveys and clarify their ensuing structures. Second, in order to understand the relationship between the employees' perceptions of job characteristics, self-regulated learning and AWCL, Pearson correlation analysis was adopted and the results of were utilised to build the hypothesised paths. A path analysis was then conducted to explore the roles employees' self-regulated learning plays in their job characteristics and AWCL.

\section{Results}

\section{Factor analysis of the job characteristics, self-regulated learning and AWCL scales (research question 1)}

This study performed an exploratory factor analysis to validate the job characteristics, self-regulated learning and AWCL questionnaires. Table 1 shows the factor analysis result of the job characteristics with 12 items. A total of 59.75\% variance was explained by the three factors: job demand ( 4 items, $\alpha=0.74$ ), job control (4 items, $\alpha=0.70$ ), and social support ( 4 items, $\alpha=0.83$ ). The overall $\alpha$ value was 0.75 , which indicates acceptable internal consistency. 
Table 1

Rotated factor loadings and Cronbach's alpha values for the three scales of job characteristics

\begin{tabular}{|c|c|c|}
\hline Item & Measure & Factor loading \\
\hline \multicolumn{3}{|c|}{ Factor 1: Job demand, $\alpha=0.74, M=2.20, S D=0.63$} \\
\hline & • My job requires me to work very fast. & 0.67 \\
\hline & - My job requires me to work very hard. & 0.73 \\
\hline & - My work needs my attention for a long time. & 0.73 \\
\hline & - My work is very busy. & 0.82 \\
\hline \multicolumn{3}{|c|}{ Factor 2: Job control, $\alpha=0.70, M=2.81, S D=0.69$} \\
\hline & - My work requires me to be creative. & 0.71 \\
\hline & - I get to do a variety of things in my job. & 0.68 \\
\hline & - My work allows me to make my own decisions. & 0.78 \\
\hline & - My opinions are influential in what happens in my work. & 0.68 \\
\hline \multicolumn{3}{|c|}{ Factor 3: Social support, $\alpha=0.83, M=1.95, S D=0.53$} \\
\hline & - My colleagues perform their duties well. & 0.73 \\
\hline & - My colleagues are caring towards me. & 0.81 \\
\hline & - My colleagues are very friendly. & 0.86 \\
\hline & - My colleagues help me with my work when I am in need of help. & 0.82 \\
\hline
\end{tabular}

As shown in Table 2, there were, respectively, two factors in the self-regulated learning questionnaire: basic self-regulated learning ( 3 items, $\alpha=0.77$ ) and advanced self-regulated learning (3 items, $\alpha=0.81$ ), with a total of $70.56 \%$ of the variance explained. The overall $\alpha$ coefficient was 0.89 . This is consistent with the assumption of this study and identifies two levels in the employees' self-regulated learning when learning online.

Table 2

Rotated factor loadings and Cronbach's alpha values for the two subscales of self-regulated learning

\begin{tabular}{|c|c|c|}
\hline Item & Measure & Factor loading \\
\hline \multicolumn{3}{|c|}{ Factor 1: Basic self-regulated learning, $\alpha=0.77, M=1.99, S D=0.60$} \\
\hline & $\begin{array}{l}\text { - When learning online, I set goals for learning the materials I am interested } \\
\text { in. }\end{array}$ & 0.84 \\
\hline & $\begin{array}{l}\text { When learning online, I put forward the learning problems I want to know } \\
\text { more about and explore online to deeply understand a certain problem. }\end{array}$ & 0.59 \\
\hline & - When learning online, I can decide on appropriate learning strategies. & 0.81 \\
\hline \multicolumn{3}{|c|}{ Factor 2: Advanced self-regulated learning, $\alpha=0.81, M=2.18, S D=0.63$} \\
\hline & $\begin{array}{l}\text { - I can learn at my own pace with online learning so that I can master the } \\
\text { learning materials I need. }\end{array}$ & 0.73 \\
\hline & $\begin{array}{l}\text { - I can evaluate the effectiveness of the online learning results to fit my } \\
\text { needs in the following matters. }\end{array}$ & 0.77 \\
\hline & $\begin{array}{l}\text { - I can improve my online learning approaches in order to solve the matters } \\
\text { I need. }\end{array}$ & 0.85 \\
\hline
\end{tabular}

As shown in Table 3, the factor analysis of the employees' responses on the AWCL questionnaire reveals that a total of 16 items corresponded to the four factors: usefulness ( 5 items, $\alpha=0.86$ ), ease of use ( 4 items, $\alpha=$ 0.85), behaviour ( 4 items, $\alpha=0.85$ ), and affection (3 items, $\alpha=0.87$ ). The overall $\alpha$ coefficient for these scales was 0.89 . Table 3 shows that some items in the affection scale were scored in a reverse manner. These factors could explain $72.19 \%$ of the total variance. Hence, these results indicate that the AWCL questionnaire is an adequate instrument for examining the employees' AWCL. 
Table 3

Rotated factor loadings and Cronbach's alpha values for the four subscales of the AWCL

\begin{tabular}{|c|c|c|}
\hline Item & Measure & Factor loading \\
\hline \multicolumn{3}{|c|}{ Factor 1: Usefulness, $\alpha=0.89, M=2.20, S D=0.68$} \\
\hline & Web-based continuing learning makes my work more interesting. & 0.71 \\
\hline & Web-based continuing learning helps to increase my creativity at work. & 0.80 \\
\hline & Web-based continuing learning can facilitate the development of my work. & 0.71 \\
\hline & Web-based continuing learning can effectively enhance my learning. & 0.75 \\
\hline & Web-based continuing learning can help me study or work more efficiently. & 0.67 \\
\hline \multicolumn{3}{|c|}{ Factor 2: Ease of use, $\alpha=0.82, M=2.04, S D=0.68$} \\
\hline & $\begin{array}{l}\text { It is easy to get web-based continuing learning to do what I want it to in the } \\
\text { workplace. }\end{array}$ & 0.75 \\
\hline & It is convenient to receive training on the job using web-based continuing learning. & 0.74 \\
\hline & The flexibility of web-based continuing learning enables me to learn more easily. & 0.71 \\
\hline & $\begin{array}{l}\text { It is easy for me to solve problems at work when I participate in web-based } \\
\text { continuing learning. }\end{array}$ & 0.59 \\
\hline \multicolumn{3}{|c|}{ Factor 3: Behaviour, $\alpha=0.85, M=2.39, S D=0.71$} \\
\hline & I hope to use web-based continuing learning more often. & 0.72 \\
\hline & $\begin{array}{l}\text { Web-based continuing learning can improve my willingness to take part in in- } \\
\text { service education. }\end{array}$ & 0.70 \\
\hline & I want to increase my use of web-based continuing learning in the future. & 0.75 \\
\hline & I am willing to recommend others to participate in web-based continuing learning. & 0.70 \\
\hline \multicolumn{3}{|c|}{ Factor 4: Affection, $\alpha=0.87, M=2.74, S D=0.91$} \\
\hline & Participating in web-based continuing learning makes me feel anxious. & 0.90 \\
\hline & $\begin{array}{l}\text { Participating in web-based continuing learning makes me feel awkward or } \\
\text { uncomfortable. }\end{array}$ & 0.91 \\
\hline & I think it is boring to use web-based continuing learning. & 0.83 \\
\hline
\end{tabular}

\section{Correlations among job characteristics, self-regulated learning and AWCL scales (research question 2)}

This study conducted Pearson correlations to examine the relationships among the airline employees' perceptions of job characteristics, self-regulated learning and AWCL. Considering the relationship between the employees' perceptions of job characteristics and AWCL, job demand did not have any significant correlation with any other variables (see Table 4). Additionally, the coefficients of the correlations for AWCL with job control and perceived usefulness was $0.23(p<.01)$, perceived ease of use was $0.19(p<.01)$ and behaviour was $0.29(p<.001)$. Moreover, social support for job characteristics was highly correlated with the AWCL scales, except that social support was the lowest correlated to affection $(r=0.16, p<.05)$. These results reveal that attitudes towards web-based continuing learning were positively correlated to job control and social support. In contrast, job control had a significant negative relationship with affection for AWCL ( $r$ $=-0.28, p<.001)$. These results are worthy of note and will be explained later in the Discussion and conclusions section. 
Table 4

Correlations among self-regulated learning, job characteristics and AWCL scales

\begin{tabular}{lllllll}
\hline & $\begin{array}{l}\text { Basic self- } \\
\text { regulated } \\
\text { learning }\end{array}$ & $\begin{array}{l}\text { Advanced } \\
\text { self-regulated } \\
\text { learning }\end{array}$ & Usefulness & $\begin{array}{l}\text { Ease } \\
\text { of use }\end{array}$ & Behaviour & Affection \\
\hline Job demands & .09 & .11 & .10 & .09 & .11 & -.12 \\
Job control & $.18^{* *}$ & $.32^{* * *}$ & $.23^{* *}$ & $.19^{* *}$ & $.29^{* * *}$ & $-.28^{* * *}$ \\
Job support & $.41^{* * *}$ & $.41^{* * *}$ & $.27^{* * *}$ & $.28^{* * *}$ & $.28^{* * *}$ & $.16^{*}$ \\
$\begin{array}{l}\text { Basic self-regulated } \\
\text { learning }\end{array}$ & --- & -- & $.55^{* *}$ & $.61^{* * *}$ & $.52^{* * *}$ & $.15^{*}$ \\
$\begin{array}{l}\text { Advanced self- } \\
\text { regulated learning }\end{array}$ & --- & -- & $.63^{* * *}$ & $.63^{* * *}$ & $.56^{* * *}$ & .01 \\
\hline
\end{tabular}

$* * p<.01, * * * p<.001$

\section{Path analysis of job characteristics, self-regulated learning and AWCL scales (research question 3)}

To understand the roles that employees' self-regulated learning and job characteristics play in their AWCL, the study conducted a path analysis to examine the relationships among these variables. As shown in Figure 1, it was interesting to note that affection $(\beta=-0.34, p<0.001)$ was negatively predicted by job control for job characteristics. These results may suggest that some airline employees with high job control may not show positive feelings towards gaining further professional development through web-based continuing learning.

We then added the self-regulated learning variables as mediators between the job characteristics and AWCL scales. It was found that advanced self-regulated learning mediates the relationships between job control $(\beta=$ $0.24, p<.001)$ of job characteristics and usefulness $(\beta=0.48, p<.01)$, ease of use $(\beta=0.39, p<.001)$ and behaviour $(\beta=0.34, p<.001)$ for AWCL. Consequently, this result highlights that job control is associated with AWCL. Employees with high job control who showed a tendency towards advanced self-regulation had a more positive perception of usefulness, ease of use and behaviour when using online workplace learning.

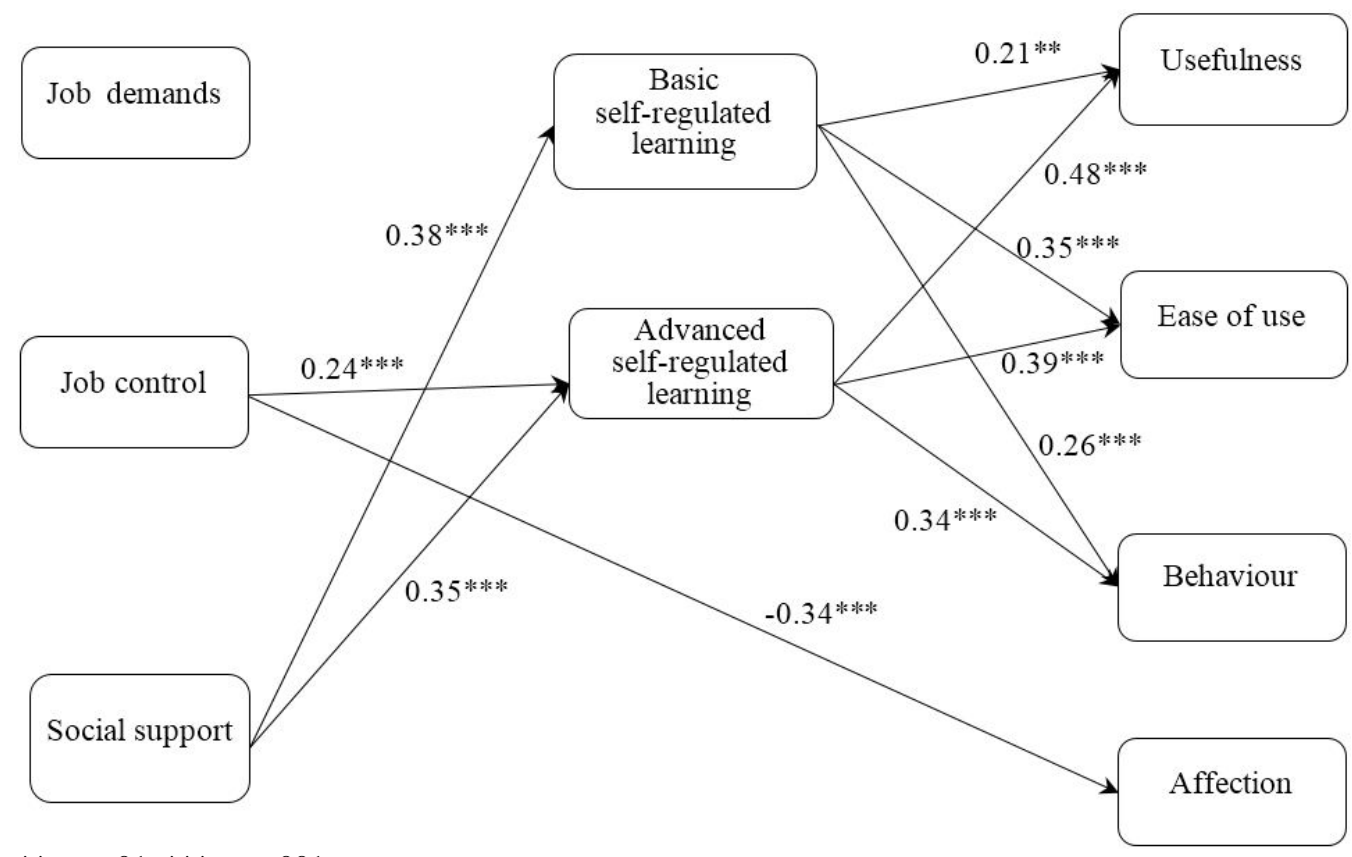

$* * p<.01, * * * p<.001$

Figure 1. Path analysis examining the relationships between self-regulated learning variables, job characteristics and AWCL scales 
Furthermore, it was found that both basic self-regulated learning and advanced self-regulated learning mediate the relationships between social support and the AWCL factors, perceived usefulness, perceived ease of use and behaviour. The paths from social support for job characteristics to AWCL through basic selfregulated learning $(\beta=0.38, p<.001)$ and advanced self-regulated learning $(\beta=0.35, p<.001)$ were significant. In addition, the paths from basic self-regulated learning to perceived usefulness, perceived ease of use and behaviour were significant $(\beta=0.21,0.35,0.26$, respectively) and those from advanced self-regulated learning were also significant and larger $(\beta=0.48,0.39,0.34$, respectively). Therefore, these results attach importance to social support and self-regulated learning. It cannot be ignored that social support from colleagues and supervisors would significantly foster attitudes towards web-based continuing learning only through self-regulated learning.

Moreover, when adding the self-regulated learning variables as mediators between job characteristics and AWCL scales, neither basic self-regulation nor advanced self-regulation show significant mediating effects on the relationships between job demands for job characteristics and AWCL. Changes in job demand may not be helpful in explaining any significant variation in AWCL. Accordingly, the study results suggest that job control and social support should receive more attention than job demand. Furthermore, through selfregulated learning, both job control and social support had a significant influence on AWCL, while only job control directly predicted affection of AWCL. This result reveals that by indirectly predicting AWCL through self-regulated learning job characteristics could play a more important role, in comparison to the path by which they directly predict AWCL.

\section{Discussion and conclusions}

The aim of this study was to examine the correlation related to employees' perceptions of job characteristics, self-regulated learning and AWCL. By using exploratory factor analysis, the results show adequate reliability and validity of the three questionnaires. By using Pearson correlation analysis and path analysis, the current study identified that both employees' self-regulated learning (personal factors) and job characteristics (workrelated variables) could predict AWCL. Moreover, self-regulated learning played a significantly mediating role between job characteristics and AWCL.

The relationship between two scales has been proved according to the aforementioned literature, such as selfregulated learning predicting AWCL (Hsiao, Tsai, Lin, \& Lin, 2012) and job characteristics predicting AWCL (Chiu et al., 2013). However, little research has been conducted on the relationship between and among the three. In contrast to previous studies, the present study has further identified that job characteristics (i.e., job control and social support) significantly predict AWCL through the mediated effect of employees' self-regulated learning. This result predicted that employees with high job control who showed a tendency towards advanced self-regulation positively perceived usefulness, ease of use and willingness when using web-based continuing learning. These findings are, to some extent, in line with those of Kyndt, Donche, Gijbels, and Van Petegem (2014), which demonstrated that learners' job control influenced their learning achievement with a mediation effect of goal orientation. The results of this study highlight the importance of job control and self-regulated learning because job control could predict AWCL through self-regulated learning. Therefore, it is recommended that supervisors could promote employees' job control by optimising workflow, thus enhancing their self-regulation in web-based continuing learning. Based on these approaches, it is beneficial to help employees increase their self-regulated learning and feeling of job control in order to facilitate the learning outcomes and their AWCL.

Another interesting finding is the importance of social support for self-regulated learning, because social support from colleagues and supervisors significantly predicts AWCL only through self-regulated learning. This result might be better explained from the perspectives of both social support and self-regulated learning. On the one hand, Lin, $\mathrm{Hu}, \mathrm{Hu}$, and Liu (2016) demonstrated the benefits of web-based learning because learners could seek online support, while tutors could provide guidance online (via communicative platforms such as emails, instant messaging applications, blogs). On the other hand, Za et al. (2014) demonstrated that employees who are inclined to learn through the processes of reflecting, sharing, receiving support and 
making adjustments (i.e., self-regulation) could effectively offer different contexts to foster transfer of their knowledge gained from oversimplified cases to conceptually complex situations. This could be conceptualised as one aspect of social support through the mediation of self-regulated learning, which is essential for better workplace learning. Thus, it is proposed that airlines should favour support services provided by supervisors, instructors and peers to construct a supplemental e-training environment and activate employees’ self-regulated learning behaviour.

Surprisingly, as with Chiu et al.’s (2013) study, this study further supports the idea that job demands may not explain a significant effect on AWCL, while job control and social support predict AWCL both directly and indirectly. Mikkelsen, Øgaard, and Landsbergis (2005) found that some dimensions of job demands (e.g., quantitative demands and secure demands) are not associated with outcome variables. In some instances, compared with online learning, airline employees focus more on situations, drill and practice. As Niewolny and Wilson (2009) stressed in their study, situated and tool-mediated activity paradigms as complex set of social practices play an important role in adults' learning psychologically and locally. This suggests that instead of job demands, airlines should pay more attention to improving employees' job control and social support.

In addition, the results of this study reveal that employees' anxiety regarding web-based continuing learning increases when they are required to make decisions related to their work (i.e., high job control), which differs from previous studies (e.g., Chiu et al., 2013). Kotrlik and Redmann (2005) confirmed that adult employees felt some anxiety towards technology, although they perceived the benefits that come with using it effectively. They further demonstrated that technology anxiety might be reduced if employees understand the process that they would have to undergo when using technology. Essentially, there are two other main attitudes towards online learning. Firstly, according to Kim and Merriam's (2010) study, when asked, adults responded that in order to "save face" (p. 452) they would not turn to others for help. Secondly, this study found that experienced employees preferred to build new knowledge and identities than receive knowledge from instructors passively. Thus, it is important for educators to create a respectful and individually sensitive learning environment where learners are provided with more learning autonomy, and can contribute proactively in structured group work or participate constructively in online community building. Since webbased continuing learning is a current trend in the workplace, workplace educators or researchers should find ways to help senior employees reduce their anxiety and increase their confidence in web-based learning environments. Therefore, future research could examine how to encourage senior employees to engage in web-based continuing learning and provide more opportunities to build positive experiences.

\section{Limitations}

This study has some limitations. First, the majority of participants were young employees. Hence, future research should repeat and test the path analysis model with more stringent and wider samples (e.g., senior employees). Second, it would be interesting to design an intervention experiment that considered selfregulated learning and job characteristics. Finally, a longitudinal follow-up of the respondents of this study might be valuable, because it would allow causal relationships regarding the influence of self-regulated learning and job characteristics on online work-related learning to be identified.

\section{Implications}

First, our study contributes to the conceptual framework of growing evidence based on the dynamic interplay of job characteristics, self-regulated learning and individual attitudes. The findings deliver insights into the processes that an increase in job control and social support (i.e., job characteristics) may significantly predict airline employees' positive AWCL through the mediated effect of self-regulated learning. These are consistent with the findings of previous studies on the relationship between self-regulated learning, personal characteristics and online learning performance. Goh, Seet, and Chen's (2012) study offers vital evidence that self-regulated learning positively mediates the relationship between effective m-learning service and higher academic performance. Moreover, Scott, Sorokti, and Merrell's (2016) study suggests that when learners 
practise self-regulated learning in informal learning spaces in enterprise social network systems their levels of cognitive and online learning presence increase.

Second, our study identifies the benefits of self-regulated learning use at work. This has practical implications for airline employees' web-based continuing learning: the promotion of reflective learning, so as to enhance their awareness and understanding of their learning experiences. Furthermore, this study extends our understanding of airline employees' web-based continuing learning. To the best of our knowledge, our research pioneers the context of studying airline employees to highlight the mediating role of self-regulated learning between job characteristics and AWCL. Therefore, the implications drawn from this study suggest that the integration of personal and work-related variables should be regarded as strategies to promote successful implementations of online workplace learning performance. For instance, Delen et al. (2014) stressed that self-regulation strategy use could be increased through training and learners' self-regulatory activities. Their study further proved that embedding supplemental functions (i.e., instructional scaffolding of pedagogical values to activate learner's self-regulated learning behaviours) in an e-learning environment may enhance positive involvement and active engagement. Additionally, Sandlin and Walther (2009) also indicate that self-regulatory activities include individual practices (e.g., self-reflection) and communal means (e.g., participating in online community discussions and face-to-face groups), which help adult employees create new subjectivities. Taking a step further, it is recommended that social support and self-regulated learning should be considered as major elements when evaluating the functionality of web-based continuing learning system. Several studies support this idea, because e-learning environments provide a new source of data for tracking learning processes (e.g., Reimann, Markauskaite, \& Bannert, 2014). For instance, Reimann et al. (2014) suggest that self-regulated learning processes and multiple data sets should be investigated by simultaneously tracking observable behaviours (e.g., mouse clicks, speech) and hardly visible responses of the body and brain (e.g., brain activations, eye movement). Additionally, Chai, Deng, Tsai, Koh, and Tsai's (2015) study found that with pervasive computing technology, the provision of self-regulated learning stimulates learners' higher level learning practices (e.g., solving learning problems creatively and collaboratively). As a result, a web-based continuing learning platform which highlights the importance of self-regulated learning and social support can provide a mechanism for scaffolding employees' self-regulated abilities (Feng \& Chen, 2014), as well as timely feedback in the workplace (Thorpe \& Gordon, 2012). This would contribute more directly to helping employees when they faced with work problems and learning difficulties and would be beneficial in cultivating their continuing learning abilities.

\section{Acknowledgements}

This study was supported by the Natural Science Foundation in China (Grant \#61370178), Science and Technology Major Project of Guangdong Province (\#2015B010109003). The authors express their gratitude to the anonymous reviewers and editors for their helpful comments about this paper.

\section{References}

Chai, C. S., Deng, F., Tsai, P.-S., Koh, J. H. L., \& Tsai, C.-C. (2015). Assessing multidimensional students’ perceptions of twenty-first-century learning practices. Asia Pacific Education Review, 16(3), 389-398. doi:10.1007/s12564-015-9379-4

Chai, C. S., Wong, L. H., \& King, R. B. (2016). Surveying and modeling students’ motivation and learning strategies for mobile-assisted seamless Chinese language learning. Journal of Educational Technology \& Society, 19(3), 170-180. Retrieved from http://www.jstor.org/stable/jeductechsoci.19.3.170

Chen, H.-J. (2010). Linking employees' e-learning system use to their overall job outcomes: An empirical study based on the IS success model. Computers \& Education, 55(4), 1628-1639. doi:10.1016/j.compedu.2010.07.005

Chen, H. J., \& Kao, C. H. (2012). Empirical validation of the importance of employees' learning motivation for workplace e-learning in Taiwanese organisations. Australasian Journal of Educational Technology, 28(4), 580-598. doi:10.14742/ajet.829 
Cheng, B., Wang, M. H., Moormann, J., Olaniran, B. A., \& Chen, N. S. (2012). The effects of organizational learning environment factors on e-learning acceptance. Computers \& Education, 58(3), 885-899. doi:10.1016/j.compedu.2011.10.014

Cheng, K.-H., Liang, J.-C., \& Tsai, C.-C. (2013). University students’ online academic help seeking: The role of self-regulation and information commitments. The Internet and Higher Education, 16, 70-77. doi:10.1016/j.iheduc.2012.02.002

Cheng, Y., Chen, I. S., Burr, H., Chen, C. J., \& Chiang, T. L. (2014). Changes in psychosocial work conditions in Taiwanese employees by gender and age from 2001 to 2010. Journal of Occupational Health, 55(5), 323-332. doi:10.1539/joh.12-0286-OA

Chiu, Y. L., \& Tsai, C. C. (2014). The roles of social factor and internet self-efficacy in nurses' web-based continuing learning. Nurse Education Today, 34(3), 446-450. doi:10.1016/j.nedt.2013.04.013

Chiu, Y. L., Tsai, C. C., \& Fan Chiang, C. Y. (2013). The relationships among nurses' job characteristics and attitudes toward web-based continuing learning. Nurse Education Today, 33(4), 327-333. doi:10.1016/j.nedt.2013.01.011de Brito Neto, J. F., Smith, M., \& Pedersen, D. (2014). E-learning in multicultural environments: An analysis of online flight attendant training. British Journal of Educational Technology, 45(6), 1060-1068. doi:10.1111/bjet.12180

Delen, E., Liew, J., \& Willson, V. (2014). Effects of interactivity and instructional scaffolding on learning: Self-regulation in online video-based environments. Computers \& Education, 78, 312-320. doi:10.1016/j.compedu.2014.06.018

Feng, C.-Y., \& Chen, M.-P. (2014). The effects of goal specificity and scaffolding on programming performance and self-regulation in game design. British Journal of Educational Technology, 45(2), 285302. doi:10.1111/bjet.12022

Gijbels, D., Raemdonck, I., \& Vervecken, D. (2010). Influencing work-related learning: The role of job characteristics and self-directed learning orientation in part-time vocational education. Vocations and Learning, 3(3), 239-255. doi:10.1007/s12186-010-9041-6

Goh, T.-T., Seet, B.-C., \& Chen, N.-S. (2012). The impact of persuasive SMS on students' self-regulated learning. British Journal of Educational Technology, 43(4), 624-640. doi:10.1111/j.14678535.2011.01236.X

Hsiao, H. S., Tsai, C. C., Lin, C. Y., \& Lin, C. C. (2012). Implementing a self-regulated WebQuest learning system for Chinese elementary schools. Australasian Journal of Educational Technology, 28(2), 315-340. doi:10.14742/ajet.876

Joo, Y. J., Lim, K. Y., \& Park, S. Y. (2011). Investigating the structural relationships among organisational support, learning flow, learners' satisfaction and learning transfer in corporate e-learning. British Journal of Educational Technology, 42(6), 973-984. doi:10.1111/j.1467-8535.2010.01116.x

Karasek, R., Brisson, C., Kawakami, N., Houtman, I., Bongers, P., \& Amick, B. (1998). The Job Content Questionnaire (JCQ): An instrument for internationally comparative assessments of psychosocial job characteristics. Journal of Occupational Health Psychology, 3(4), 322-355. doi:10.1037/10768998.3.4.322

Kim, Y. S., \& Merriam, S. B. (2010). Situated learning and identity development in a Korean older adults’ computer classroom. Adult Education Quarterly, 60(5), 438-455. doi:10.1177/0741713610363019

Kotrlik, J. W., \& Redmann, D. H. (2005). Extent of technology integration in instruction by adult basic education teachers. Adult Education Quarterly, 55(3), 200-219. doi:10.1177/0741713605274630

Kyndt, E., Donche, V., Gijbels, D., \& Van Petegem, P. (2014). Workplace learning within teacher education: The role of job characteristics and goal orientation. Educational Studies, 40(5), 515-532. doi:10.1080/03055698.2014.936829

Lehmann, T., Hähnlein, I., \& Ifenthaler, D. (2014). Cognitive, metacognitive and motivational perspectives on preflection in self-regulated online learning. Computers in Human Behavior, 32, 313-323. doi:10.1016/j.chb.2013.07.051

Liang, J.-C., Wu, S.-H., \& Tsai, C.-C. (2011). Nurses’ Internet self-efficacy and attitudes toward web-based continuing learning. Nurse Education Today, 31(8), 768-773. doi:10.1016/j.nedt.2010.11.021

Lin, K.-M. (2011). E-Learning continuance intention: Moderating effects of user e-learning experience. Computers \& Education, 56(2), 515-526. doi:10.1016/j.compedu.2010.09.017 
Lin, X., Hu, X., Hu, Q., \& Liu, Z. (2016). A social network analysis of teaching and research collaboration in a teachers’ virtual learning community. British Journal of Educational Technology, 47(2), 302-319. doi:10.1111/bjet.12234

McLoughlin, C., \& Lee, M. J. W. (2010). Personalised and self regulated learning in the Web 2.0 era: International exemplars of innovative pedagogy using social software. Australasian Journal of Educational Technology, 26(1), 28-43. doi:10.14742/ajet.1100

Mikkelsen, A., Øgaard, T., \& Landsbergis, P. (2005). The effects of new dimensions of psychological job demands and job control on active learning and occupational health. Work \& Stress, 19(2), 153-175. doi:10.1080/02678370500167808

Niewolny, K. L., \& Wilson, A. L. (2009). What happened to the promise? A critical (re)orientation of two sociocultural learning traditions. Adult Education Quarterly, 60(1), 26-45. doi:10.1177/0741713609333086

Peng, H., Tsai, C. C., \& Wu, Y. T. (2006). University students’ self-efficacy and their attitudes toward the Internet: The role of students’ perceptions of the Internet. Educational Studies, 32(1), 73-86. doi:10.1080/03055690500416025

Pintrich, P. R. (2000). The role of goal orientation in self-regulated learning. In M. Boekaerts, P. R. Pintrichve \& M. Zeidner (Eds.), Handbook of self-regulation (pp. 451-502). San Diego, CA: Academic Press. doi:10.1016/B978-012109890-2/50043-3

Reimann, P., Markauskaite, L., \& Bannert, M. (2014). e-Research and learning theory: What do sequence and process mining methods contribute? British Journal of Educational Technology, 45(3), 528-540. doi:10.1111/bjet.12146

Sandlin, J. A., \& Walther, C. S. (2009). Complicated simplicity moral identity formation and social movement learning in the voluntary simplicity movement. Adult Education Quarterly, 59(4), $298-317$. doi:10.1177/0741713609334137

Scott, K. S., Sorokti, K. H., \& Merrell, J. D. (2016). Learning “beyond the classroom” within an enterprise social network system. The Internet and Higher Education, 29, 75-90. doi:10.1016/j.iheduc.2015.12.005

Taris, T. W., \& Kompier, M. A. (2004). Job characteristics and learning behavior: review and psychological mechanisms. In P. L. Perrewe \& D. C. Ganster (Eds.), Exploring interpersonal dynamics (Research in occupational stress and well-being (Vol. 4, pp.127-166). Bingley, WY: Emerald Group Publishing Limited. doi:10.1016/S1479-3555(04)04004-1

Thorpe, M., \& Gordon, J. (2012). Online learning in the workplace: A hybrid model of participation in networked, professional learning. Australasian Journal of Educational Technology, 28(8), 1267-1282. doi:10.14742/ajet.763

Tseng, S. C., Liang, J. C., \& Tsai, C. C. (2014). Students' self-regulated learning, online information evaluative standards and online academic searching strategies. Australasian Journal of Educational Technology, 30(1), 106-121. doi:10.14742/ajet.242

Weigl, M., Müller, A., Hornung, S., Leidenberger, M., \& Heiden, B. (2014). Job resources and work engagement: The contributing role of selection, optimization, and compensation strategies at work. Journal for Labour Market Research, 47(4), 299-312. doi:10.1007/s12651-014-0163-4

Willemse, B. M., de Jonge, J., Smit, D., Depla, M. F., \& Pot, A. M. (2012). The moderating role of decision authority and coworker-and supervisor support on the impact of job demands in nursing homes: A crosssectional study. International Journal of Nursing Studies, 49(7), 822-833. doi:10.1016/j.ijnurstu.2012.02.003

Wong, S. L., \& Abu Bakar, K. (2009). Qualitative findings of students’ perception on practice of selfregulated strategies in online community discussion. Computers \& Education, 53(1), 94-103. doi:10.1016/j.compedu.2008.12.021

Za, S., Spagnoletti, P., \& North-Samardzic, A. (2014). Organisational learning as an emerging process: The generative role of digital tools in informal learning practices. British Journal of Educational Technology, 45(6), 1023-1035. doi:10.1111/bjet.12211

Zimmerman, B. J. (2002). Becoming a self-regulated learner: An overview. Theory into Practice, 41(2), 6470. doi:10.1207/s15430421tip4102_2

Zimmerman, B. J., \& Kitsantas, A. (2014). Comparing students' self-discipline and self-regulation measures and their prediction of academic achievement. Contemporary Educational Psychology, 39(2), $145-155$. doi:10.1016/j.cedpsych.2014.03.004 
Corresponding author: Q. Hu, 2013010048@m.scnu.edu.cn

Australasian Journal of Educational Technology @ 2018.

Please cite as: Lin, X.-F., Liang, J.-C., Tsai, C.-C., \& Hu, Q. (2018). The moderating role of self-regulated learning in job characteristics and attitudes towards web-based continuing learning in the airlines workplace. Australasian Journal of Educational Technology, 34(1), 102-115.

https://doi.org/10.14742/ajet.3198 